\title{
THE USE OF VOCABULARY LEARNING STRATEGIES BY MUSIC AND DANCE LEARNERS OF THE STATE UNIVERSITY OF SURABAYA
}

\author{
Yuri Lolita \\ Universitas Negeri Surabaya \\ yurilolita@unesa.ac.id \\ Nur Fauzia \\ Universitas Negeri Surabaya \\ nurfauzia@unesa.ac.id
}

\begin{abstract}
This study was conducted to examine the use of vocabulary learning strategies (VLSs) by Music and Dance students as well as the impact of gender and grade levels on the use of learning strategies. A five Likert scale questionnaire, consisting of 36 items was classified under four strategy categories was administrated to 466 participants from the State University of Surabaya. There are male and female. The Statistical Package of Social Science (SPSS, version 20) was used to analyze the obtained data. The results of the descriptive statistics showed that The State university of Surabaya students were medium strategy users. The study also found that the cognitive strategies were the most popular strategies among the learners. Social strategies were found to be the least preferred strategies. The results of the t-test showed that in general, the scores of female learners regarding the use of VLSs were slightly higher than male learners. Moreover, Music learners were found to be more strategy users than Dance learners. The results of ANOVA revealed significant differences regarding the use of VLSs and grade levels.
\end{abstract}

Keywords: Vocabulary learning strategies, Music/Dance learners

\section{INTRODUCTION}

Vocabulary knowledge plays an important role in learning English as a Second Language (ESL). Vocabulary learner strategies have come to the fore as an important area of research into vocabulary. It can be learned through incidental learning or direct intentional learning. Nation (2001) suggested that incidental learning is more likely to occur when students have a high-proficiency level and might read for pleasure. Accordingly, VLSs are teachable, that language learners can be taught various kinds of VLSs and how to practice them effectively. Read (2000: 1) stated that "words are the basic building block of language, the units of meaning from which larger structures such as sentences, paragraphs and whole text are formed". The previous statement shows the importance of vocabulary in expressing thoughts and conveying meanings and it can also be an indicator that communication will poorly be understood without a large number of words. Students have rarely been taught that they should gain efficient knowledge of vocabulary in order to produce meaningful sentences. Language learners should 
be taught VLSS in order to be able to determine the meanıng of new words and memorize them. Thornbury (2005) declared that the good language learners are those students who are able to develop their own VLSs so that they do not need to be taught how to learn. Learners spend much time on memorizing words but unfortunately, they face problems and cannot communicate well when they need them. The good language learners are those who use efficient VLSs and control their vocabulary learning. This means selecting the most suitable strategy from a variety of known strategies and determining how to follow the strategy and when to change to another one. It seems that the language teachers' main purpose is to lead students to reach a level of autonomy and make them independent from teachers in learning vocabulary.

On the other hand, the present situation of learning vocabulary with Music and Dance learners can be outlined as follows: 1) Lack of different strategies in learning vocabulary. For a long time, there has not been adequate change in vocabulary teaching methodology. Most teachers do not pay attention to VLSs. 2) Inefficient ways of learning vocabulary. Generally, learners mechanically memorize vocabulary without being aware of other effective learning strategies. It is important to find effective strategies of learning vocabulary. Based on the problems mentioned above, this study might help teachers and learners to become aware of the importance of vocabulary and solve those problems to enhance the development of the language learning process. If the findings reveal that the learners are not familiar with a wide range of VLSs; this research might help language teachers become aware of different VLSs. Besides, a study of this type will aid students to choose the strategies that are appropriate to their learning styles.

\section{LITERATURE REVIEW \\ Vocabulary Learner Strategies}

Learning vocabulary is considered as essential part when communication in second or foreign language (Read, 2000; Meara, 2002; Al-Khasawneh, 2012). Learning strategies are "special thoughts or behaviors that individuals use to comprehend, learn or retain new information" (O'Malley and Chamot, 1990: 1). VLS means any devices, tools or techniques used by the language learners to retain their vocabulary easily. Nation (1990) asserts that most of language learners' problems in both receptive and productive usage of vocabulary emerge from their insufficient learning of lexical knowledge. VLSs must contain strategies for learning a word, in addition to using a word. Hedge (2000) proposes that in addition to the teachers' explanation of the new words to learners, one of their main crucial roles is to improve independence among learners by teaching them effective strategies. Accordingly, VLSs are teachable, that language learners can be taught various kinds of VLSs and how to practice them effectively. Therefore, language learners need to be familiar with a variety of VLSs and acknowledged with a selection of VLS and are taught how to employ them in order to build up their vocabulary or to resolve the problems they face in learning vocabulary effectively.

In the language classroom, VLSs taught probably build learners' selfconfidence to learn vocabulary autonomously. In order to deal with a new word when it occurs and be successful and independent language learners, Harmer 
(1991) stated that language learners should be familiarized with extensive kinds of strategies, which is very beneficial since they become able to select the type of strategies that are appropriate to their individual learning styles. LLSs create a better self-direction for language learners. Oxford (1990) pointed that independent language learners are self-directed learners, who have the responsibility for their own learning strategies and progressively obtain confidence and proficiency. Schmitt (1997) declared that learners are widely inclined to employ basic VLSs. This in turn makes VLS instruction an important part of foreign or SLL. Language teachers need a good knowledge of VLS that could be useful to plan their teaching more successfully and guide learners in adopting effective strategies. Therefore, training in the VLSs is necessary for language learners.

\section{Classification of Vocabulary Learning Strategies}

According to Schmitt (1997) that investigated many learning strategies altogether in his own classification of VLS. He distinguished between the strategies that learners use to determine the meaning of unknown words when they first encounter them from the ones learners use to consolidate meanings when they encounter the words again. Schmitt classified the strategies in his taxonomy as discovery strategies (social and determination strategies) and consolidation strategies (cognitive, memory, metacognitive, and social strategies for learning vocabulary). Social strategies are included in two groups of strategies because they can be used for both purposes. Lessard-Clouston (2008) stated that this categorization has been developed based on language learning strategies' classification organized by Oxford's (1990).

In discovery strategies, determination strategies are used for the discovery of a new word's meaning without attaining somebody's knowledge. According to Schmitt (1997) Schmitt defined cognitive strategies as "manipulation or transformation of the target language by the learner". Cognitive strategies refer to the repetition and employing some mechanical means for learning vocabulary. Memory strategies involve those approaches to relate the word with some existing learned knowledge. Meta-cognitive strategies are defined as a conscious overview of the learning process and they assist students to control, plan, monitor and evaluate the best ways to study. Lastly, Schmitt noted that learners try to determine the meaning of a new word by guessing it with the help of context, dictionary or through using social strategies to ask someone (e.g. teachers, their classmates) for help with unfamiliar words. Group learning work through which learners study and practice the meaning of new words is an example of social strategies for consolidating a word.

\section{METHOD}

This study collected data using a survey design. According to Kraemer (1991: 13), Survey design identified three distinguishing characteristics of survey research. First, survey design is used to quantitatively describe specific aspects of a given population. These aspects often involve examining the relationships among variables. Second, the data required for survey research are collected from people and are, therefore, subjective. Finally, survey design uses selected portion of the population from which the finding can later be generalized back to the population. 
The Use of Vocabulary Learning Strategies by Music and Dance Learners of the State University of Surabaya

\section{Participants}

Table 1 shows the distribution of students according to gender and field of study.

Table 1: Distribution of students according to their gender and field of study

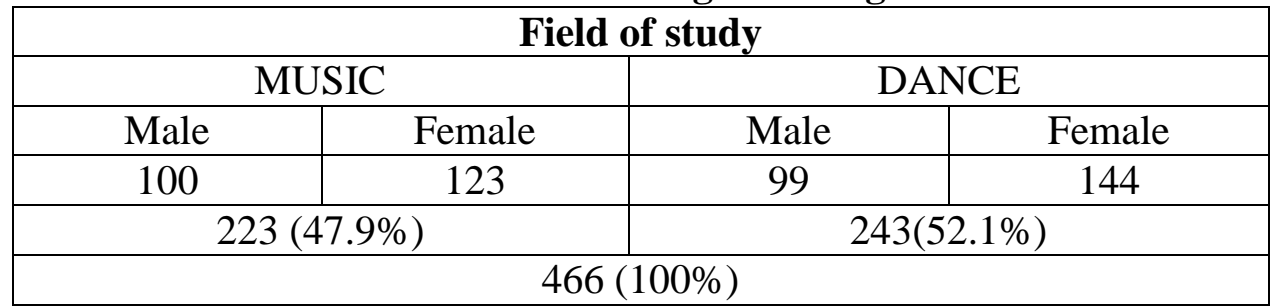

The subject includes 466 students at Universitas Negeri Surabaya. The data were collected from the Faculty of language and arts. The study included 223 of the participants were MUSIC students and 243 were DANCE students.

\section{Instrument}

In this process, a written VLS questionnaire was used as a main instrument in order to identify patterns and preferences of the participants' use of VLSs. The questionnaire used in this study is the one developed by Tek (2006) who relied mainly on the study conducted by Schmitt (1997). This questionnaire was chosen because the researcher believed that they are close to the samples in his study. The questionnaire consists of two parts. In the first part, questions are designed to gain demographic information about participants. Questions in this section include the respondents' gender and grade level. The second part includes the questions related to the VLSs. The questionnaire contains 36 items. The items are divided into four categories, social, memory, cognitive and metacognitive. Each category consists of nine items. To find the frequency of use for each strategy, a five point Likert scale was used with the options, (1)“never", (2)“sometimes", (3)“often", (4)"usually", and (5)“always".

\section{Data Collection, Procedure and Analysis}

All the data were collected during the second semester of academic year 2017. During a 60 minutes lesson, the students were asked to answer a set of questionnaires. The researcher reminded them to answer questionnaires individually. They were required to reflect on the strategies, they were not allowed to discuss their choice of language learning strategies with others. This was to ensure that each of the student's answer was not influenced by their peers. The data was then analyzed using the computer program called Statistical Package for the Social Science. The descriptive statistic was used to see the frequency, the percentage and the vocabulary learning strategies employed by the learners.

\section{RESULTS AND DISCUSSIONS \\ The Frequency of Usage of VLS Categories}

To locate the most and least frequently used VLS categories, descriptive statistics, including means and standard deviations of the four categories were calculated. Table 2 shows the frequency of strategy use of the four categories. 
Table 2: The mean score and standard deviation of the four categories of VLSs

\begin{tabular}{|l|c|c|c|c|}
\hline Strategy main category & Number & Mean & S.D. & $\begin{array}{c}\text { Strategy } \\
\text { level }\end{array}$ \\
\hline Cognitive & 466 & 3.32 & 1.10 & Medium \\
\hline Memory & 466 & 3.10 & 1.08 & Medium \\
\hline Metacognitive & 466 & 2.92 & 1.16 & Medium \\
\hline Social & 466 & 2.71 & 1.14 & Medium \\
\hline
\end{tabular}

The results in table 3 show that the Music and Dance learners used all four categories of VLSs moderately. Therefore, the students reported only averagelevel use of VLSs of any category $(\mathrm{M}=2.98)$. Cognitive strategies $(\mathrm{M}=3.32 ; \mathrm{SD}=$ 1.10) were reported as the most frequently used strategies by the respondents, followed by memory strategies $(\mathrm{M}=3.10 ; \mathrm{SD}=1.08)$ and metacognitive strategies $(\mathrm{M}=2.92 ; \mathrm{SD}=1.16)$. Social strategies $(\mathrm{M}=2.71 ; \mathrm{SD}=1.14)$ were found to be the least frequently used strategies compared to other strategies.

Cognitive strategies were found to be the most frequently used strategies. These strategies were used at the medium level of strategy use with the mean score of 3.29, but compared to the strategies of the other three categories, they were more frequently used. This result goes in line with many previous research findings (e.g., Pourshahian et al., 2012; Bengar \& Kasmani, 2013; Karami \& Barekat, 2012; Kudo, 1999; Tek, 2006). The frequent use of cognitive strategies might result from students' high English proficiency level.

\section{The Five Most Used Strategies}

Table 3: The five most preferred strategies by the students

\begin{tabular}{|l|c|c|c|}
\hline \multicolumn{1}{|c|}{ Strategy items } & Mean & SD & Rank \\
\hline Use English language internet & 3.80 & 1.17 & 1 \\
\hline Take notes in class. & 3.77 & 1.03 & 2 \\
\hline Use a bilingual dictionary & 3.69 & 1.05 & 3 \\
\hline Image word's meaning. & 3.53 & 1.11 & 4 \\
\hline Use a monolingual dictionary & 3.51 & 1.11 & 5 \\
\hline
\end{tabular}

The table 3 shows the five most frequent used VLSs by the students of this study. The results revealed that "Using internet" is the most frequent strategy among learners of this study. This means the students see the internet as a main source to find out information to learn a new word. Several years ago, the commercial internet service providers began to emerge in UNESA. Commercial internet services widespread quickly. Therefore, people in general and students in particular found the internet to be a source of new extracurricular language learning activities for them. It can be said, this new advanced technology, to some extent, motivated the students to discover new VLSs. Moreover, because of its novelty and extraordinary character, students probably started to spend much time 
working on the internet, and thus they tended to frequently come across various unknown words and thus enrich their vocabulary. Finding this strategy as the highest used strategy might also have a connection with the students' very frequent use of various forums or online exercises on the Web. On the other hand, the high frequency of using internet to learn vocabulary might be related to its accessibility.

The second most frequently used strategy is "Taking notes in class". It seems that language lectures have advised the students to memorize and take notes in class as a preparation for examination. This result was similar with the findings of some previous study.

The third popular strategy was the use of a "bilingual dictionary". The results of this study showed that the students preferred using bilingual dictionaries more than using monolingual dictionaries. This means that the learners tended more to think the meaning of the unknown word in their L1 translation. However, finding the popularity use of bilingual dictionary among the students of this study does not mean that it is a useful source for learning a word, as in the VLS literature review, Brown (2000: 377) stated, "It is unfortunate that such practices rarely help students internalize the word for later recall". Moreover, the use of a "bilingual dictionary" was criticized for several reasons, for example to encourage using the translation, provides little knowledge on how the words are used (Nation, 2001)

\section{The Five Least Used Strategies}

Table 4: The five least used strategies by the students

\begin{tabular}{|l|c|c|c|}
\hline \multicolumn{1}{|c|}{ Strategy items } & Mean & SD & Rank \\
\hline Test with your parents, if they know English & 1.90 & 1.11 & 1 \\
\hline Ask your school lecture for translation & 2.03 & 1.10 & 2 \\
\hline $\begin{array}{l}\text { Ask your lecture to check your word lists for } \\
\text { accuracy }\end{array}$ & 2.32 & 1.03 & 3 \\
\hline Listen to English- radio program & 2.45 & 1.24 & 4 \\
\hline Read an English language newspaper & 2.49 & 1.16 & 5 \\
\hline
\end{tabular}

As can be seen the table 4 that the least frequently used strategy among 36 VLSs by the students of this study was from metacognitive strategies, which was "Testing with your parent, if they know English". This finding indicates that the parents did not understand the English language therefore; the students almost never tested the meaning of the new word with them. The second and the third infrequently used strategies are from social strategies which are, "Ask your lecture for translation" and "Ask your lecture to check your word lists for accuracy". It seems that inside the language classes, interaction activities very rarely happen. The most sensible explanations for the least use of social strategies, particularly asking lectures for the L1 translation or other information to determine the meaning of a new word, is that learning vocabulary items seems to be regarded as an individual process rather than seeking help from others. These findings are also similar to that of Bengar and Kasmani's study about that the reason of the infrequent use of social strategies could be that learning English vocabulary is inclined to be seen as an individual task, therefore, when learners think to discover the meaning of the new word, they prefer not to ask help from others. 
Another reason for the rare use of asking lectures' help in learning a new word might be found in the peculiarities of the educational system. In language classrooms, lectures seem to be the centre of language learning. This means that language lectures tend to provide information and materials.

\section{Significant Differences of VLS Use Based on Gender}

The results in table 5 show the significant differences only in four individual strategies found between gender and strategy use.

Table 5: Significant differences of VLS use based on gender

\begin{tabular}{|c|c|c|c|c|c|c|c|}
\hline Strategy Items & Gender & $\mathbf{N}$ & Mean & SD & $\mathbf{T}$ & d.f & Sig \\
\hline \multirow{2}{*}{ Take notes in class } & male & 199 & 3.60 & 1.10 & \multirow{2}{*}{-3.50} & \multirow{2}{*}{464} & \multirow[t]{2}{*}{.001} \\
\hline & female & 267 & 3.90 & 3.92 & & & \\
\hline \multirow{2}{*}{$\begin{array}{l}\text { Test with your parents, } \\
\text { if they know English. }\end{array}$} & Male & 199 & 1.70 & 1.72 & \multirow{2}{*}{-3.00} & \multirow{2}{*}{464} & \multirow[t]{2}{*}{.003} \\
\hline & female & 267 & 2.00 & 2.03 & & & \\
\hline \multirow{2}{*}{$\begin{array}{l}\text { Learn by pair work in } \\
\text { class }\end{array}$} & male & 199 & 2.90 & 2.90 & \multirow{2}{*}{-3.30} & \multirow{2}{*}{464} & \multirow[t]{2}{*}{.001} \\
\hline & female & 267 & 3.20 & 3.22 & & & \\
\hline \multirow{2}{*}{$\begin{array}{l}\text { Learn by group work in } \\
\text { class }\end{array}$} & male & 199 & 3.00 & 3.00 & \multirow{2}{*}{-3.05} & \multirow{2}{*}{464} & \multirow[t]{2}{*}{.002} \\
\hline & female & 267 & 3.30 & 3.32 & & & \\
\hline
\end{tabular}

In this study, the significant differences were found only in using four strategies. Female learners were more frequent strategy users in those four strategies than male learners. The results in table 5 indicate that the female learners $(M=3.90)$ seem to take more notes in the class than the males $(M=3.60)$. This finding suggests that inside the classroom, female learners are more active and follow the lecture's instructions more than male learners. The results also show that female learners $(\mathrm{M}=2.00)$ tend to test the meaning of the new word with their parents more than male learners $(M=1.70)$.

In literature review, research studies have investigated that females talk to parents more than males, such as Noller and Callan (1991) stated, "females talk more to parents and disclose more in conversation regarding issues such as interests, family sex roles and relationships". Consequently, females are more verbally interactive with parents and receive affection from parents in general than males. Therefore, this might be a main reason that female learners used to test the meaning of the new words with their parents more than male learners. In the Kurdish background culture, females spend most of their times staying at home compared to males. Therefore, the fact that females spend more time staying at home might be another reason why they are more inclined to test the meaning of the new words with parents than males. The female learners $(M=3.20)$ showed that they preferred more to work in pairs than males $(M=2.90)$. Interestingly, the same with the frequency of use of strategy "Learn by group work in class", that females $(\mathrm{M}=3.30)$ were using it more frequently than the males $(\mathrm{M}=3.00)$.

These findings suggest that females tend to build social interaction and learn the meaning of the new word through pair or group work more than males, such as Timmers and Fischer (1998) stated that "females' communication patterns focus on relationships and females' focus on power". The most plausible explanation for the frequent use of social strategies by females could be that 
females in general are more inclined to interact and build social relationships than men. Several research studies explained that females seek for help more than males, females are more eager to keep on the need for social support and approval (Ehrman \& Oxford, 1989). Hall (2011) stated that if the idea of believing that female learners are better L2 learners than male learners is right, then probably it is resulted from their effective social interactions. These findings support the idea that the females tend to use more social strategies than males.

\section{Significant Differences of VLS Use Based on Field of Study}

Table 6: illustrates the significant differences in two major fields of study and strategy use.

\begin{tabular}{|c|c|c|c|c|c|c|c|c|}
\hline Strategy Items & $\begin{array}{c}\text { Major } \\
\text { Field }\end{array}$ & Gender & $\mathbf{N}$ & Mean & SD & $\mathbf{T}$ & d.f & Sig. \\
\hline \multirow{4}{*}{$\begin{array}{l}\text { Connect the word } \\
\text { to its synonym } \\
\text { and antonym }\end{array}$} & \multirow[t]{2}{*}{ Music } & Male $\quad(100)$ & \multirow{2}{*}{223} & \multirow[t]{2}{*}{3.30} & \multirow{2}{*}{1.06} & \multirow{4}{*}{3.60} & \multirow{4}{*}{464} & \multirow{4}{*}{.000} \\
\hline & & Female (123) & & & & & & \\
\hline & \multirow[t]{2}{*}{ Dance } & Male (99) & \multirow{2}{*}{243} & \multirow{2}{*}{2.90} & \multirow{2}{*}{1.10} & & & \\
\hline & & Female (144) & & & & & & \\
\hline \multirow{4}{*}{$\begin{array}{l}\text { Use new word in } \\
\text { sentences }\end{array}$} & \multirow[t]{2}{*}{ Music } & Male $\quad(100)$ & \multirow{2}{*}{223} & \multirow[t]{2}{*}{3.40} & \multirow{2}{*}{1.11} & \multirow{4}{*}{1.30} & \multirow{4}{*}{464} & \multirow{4}{*}{.000} \\
\hline & & Female (123) & & & & & & \\
\hline & \multirow[t]{2}{*}{ Dance } & Male (99) & \multirow{2}{*}{243} & \multirow{2}{*}{3.90} & \multirow{2}{*}{1.06} & & & \\
\hline & & Female (144) & & & & & & \\
\hline \multirow{4}{*}{$\begin{array}{l}\text { Ask your teacher } \\
\text { to check your } \\
\text { word lists for } \\
\text { accuracy }\end{array}$} & \multirow[t]{2}{*}{ Music } & Male $\quad(100)$ & \multirow{2}{*}{223} & \multirow{2}{*}{2.50} & \multirow{2}{*}{1.10} & \multirow{4}{*}{3.20} & \multirow{4}{*}{464} & \multirow{4}{*}{.002} \\
\hline & & Female(123) & & & & & & \\
\hline & Dance & Male (99) & 243 & & & & & \\
\hline & & Female (144) & 243 & 2.20 & .96 & & & \\
\hline Ask your teacher & Music & Male $(100)$ & 223 & 2.60 & .78 & & & \\
\hline for sentence & & Female (123) & 223 & 2.00 & .18 & & & \\
\hline including the new & Dance & Male (99) & & & & 5.20 & 464 & .000 \\
\hline word & & Female (144) & 243 & 2.30 & 1.15 & & & \\
\hline Memorize parts & Music & Male $(100)$ & 223 & & & & & \\
\hline of speech & & Female (123) & 223 & 3.50 & .99 & 520 & 464 & .000 \\
\hline & Dance & Male $(99)$ & & & & 5.20 & 404 & \\
\hline & & Female (144) & 243 & 3.00 & 1.04 & & & \\
\hline Use $\quad$ English & Music & Male $\quad(100)$ & & & & & & \\
\hline language internet & & $\begin{array}{l}\text { Female } \\
(123)\end{array}$ & 223 & 3.70 & 1.24 & & & \\
\hline & Dance & $\begin{array}{l}\text { Male } \\
(100)\end{array}$ & & & & $\begin{array}{c}- \\
2.80\end{array}$ & 464 & .005 \\
\hline & & $\begin{array}{l}\text { Female } \\
(144)\end{array}$ & 243 & 4.00 & 1.12 & & & \\
\hline
\end{tabular}

The findings revealed that the MUSIC and DANCE learners studying at the State University of Surabaya were more alike than different in VLS use. As can be seen from the table 6, the MUSIC learners were frequent users of the "Connect the words with its synonyms and antonyms" strategy than DANCE learners. This could be because the MUSIC lectures during their lessons focused more on connecting the word to its synonyms and antonyms. The MUSIC students preferred to use new words in sentences, ask lectures for sentence including the new word and ask lectures to check their word lists for accuracy 
more frequently than DANCE students. A close look at the high frequency of use of these strategies by the MUSIC learners shows that these strategies have more relationship with the MUSIC learners than the DANCE learners. This could be because MUSIC learners deal with the structure of sentences and grammar rules more frequently than DANCE learners. Therefore, this might have led the MUSIC students to use the new word in sentences. MUSIC students preferred to use "Memorize parts of speech" strategy to learn the meaning of a new a word more frequently than DANCE students.

The MUSIC learners might have more experience in parts of speech than DANCE learners, who rarely deal with parts of speech. The results show that the DANCE learners were more eager to use internet to find the meaning of a new word than MUSIC learners. The reason could be that when the DANCE students deal with literature, especially medieval literature, they probably face many difficult words that might not be found in modern dictionaries. Therefore, these difficult words might have affected the students to use internet to find the meaning of the new words. To summarize, it was concluded that there were minor differences between the MUSIC and DANCE learners in strategy use. In general, the MUSIC students were statistically more strategy users than the DANCE students.

\section{CONCLUSION}

Based on the results of this study, it was concluded that the students were familiar with limited VLSs. The medium level of VLS use indicated that the students were not quite aware of different VLSs. Therefore, several implications can be made based on the findings of this study:

In The State University of Surabaya music and dance classes, vocabulary was not taught explicitly, since only several VLSs among 36 strategies were popular among the students. This indicates that even language teachers might not know enough about VLSs. Therefore, this study can assist the teachers and the students to have more knowledge on VLSs. Training learners by using various strategies would probably lead to better independent learners in the language learning process. To do this, teachers need to be familiar with different kinds of VLSs at first. Then, they are required to train their learners with different learning strategies.

The least frequency of use of social strategies indicates the poor social interaction in language classes. Language teachers are required to design more cooperative learning discussions and communicative competence activities in classroom. To do this, the university first must provide a curriculum, which is more directed towards collaborative and interaction activities to enhance learning process in classes. Then, language teachers are also required to arrange suitable group activities in order to encourage learners to share ideas when learning new vocabulary. Therefore, language teachers need to be aware of the importance of incorporating strategies inside language classrooms. Moreover, language teachers should be aware of differences in VLSs preferences between male and female learners and provide different opportunities for vocabulary learning. 


\section{REFERENCES}

Ahmed, M. (1989). Vocabulary learning strategies. In P. Meara (ed). Beyond words. London: CLLT

Ali Askar, Wisam. (2016). A Survey on the Use of Vocabulary Learning Strategies by ELT and ELL Students of in Kurdistan. The 2016 International Academic Research Conference in Milan

Amirian, S. M. R., \& Heshmatifar, Z. (2013). A survey on vocabulary learning strategies: A case of Iranian EFL university students. Journal of Language Teaching and Research, 4(3), 636-641.

Bengar, A. S., \& Kasmani, M. B. (2013). The effect of vocabulary learning strategies of EFL

undergraduate students on their listening comprehension ability. Asian Journal of Social Sciences \& Humanities, 2(1), 253-259.

Boonkongsaen, N., \& Intaraprasert, CH. (2014). English vocabulary learning strategies employed by Thai tertiary-levels students with different genders and levels of vocabulary proficiency. International Journal of Scientific and Research Publications, 4(3), 1-9.

Brown, H. D. (2000). Teaching by principles: An interactive approach to language pedagogy (2nd ed.). New York: Longman.

Doczi, B. (2011). Comparing the vocabulary learning strategies of high school and university students: A pilot study. WoPaLP, 5 - 138-158.

Danceis, R. (1994). The study of second language acquisition. Oxford: Oxford University Press.

Danceis, R. (1996). Understanding Second Language Acquisition. Oxford: Oxford University Press

Ehrman, M., \& Oxford, R. (1989). Effects of sex differences, career choice and psychological type on adult language learning strategies. The Modern Language Journal, 73(1), 1-13.

Gu, P. Y. \& Johnson, R. K. (1996). Vocabulary Learning Strategies and Language Learning Outcomes. Language Learning, 46, 643-679

Hall, G. (2011). Exploring English language teaching: Language in action. New York: Routledge Hall.

Hamzah, M. S. G., Kafipour, R., \& Abdullah, S. K. (2009). Vocabulary learning strategies of Iranian undergraduate EFL students and its relation to their vocabulary size. European Journal of Social Sciences, 11(1), 39-50.

Harmer, J. (1991). The practice of English language teaching. London: Longman.

Hedge, T. (2000). Teaching and learning in the language classroom. Oxford: Oxford University Press.

Heidari, F., Izadi, M., \& Ahmadian, M. V. (2012). The relationship between Iranian EFL learners' self-efficacy beliefs and use of vocabulary learning strategies. Canadian Center of Science and Education, 5(2), 174-182.

Hunt, A. \& Beglar, D. (2005). A framework for developing EFL reading vocabulary. Reading in a foreign language, 17(1) 
Karami, S., \& Barekat, B. (2012). Vocabulary learning strategies: The effect of level of proficiency on the strategy use. Trends in Advanced Science and Engineering, 6(1), 79-87.

Kraemer, K.L. (1991). Introduction. Paper Presented at The information System Reseaarch Chalenge: Survey Research Methods

Kudo, Y. (1999). L2 vocabulary learning strategies. Retrieved October 18, 2013, from http://nflrc.hawaii.edu/NetWorks/NW14.pdf

Lessard-Clouston, M. (2008). Strategies and success in technical vocabulary learning: Students' approaches in one academic context. Indian Journal of Applied Linguistics,34(1-2), 31- 63.

Macro, E. (2003). Teaching and learning a second language: A guide to recent research and its approaches. London: Continuum.

Nation, I.S.P. (1990). Teaching and Learning Vocabulary. Boston: Heinle \& Heinle.

Nation, P. (2001). Learning vocabulary in another language. Cambridge: Cambridge University Press.

Noller, P. \& Callan, V. (1991). The adolescent in the family. New York: Routledge .

Oxford, R. (1990). Language learning strategies: What every lecture should know. New York. Newbury house.

Oxford, R., \& Crookall, D. (1990). Vocabulary learning: A critical analysis of techniques. TESL Canada Journal, 7(2), 9-30.

Pourshahian, B., Azarfam, A. Y., \& Kalajahi, S. A.R. (2012). Does applying vocabulary learning strategies vary based on gender? The case of Turkish EFL learners. The International Institute for Science, Technology and Education (IISTE), 2(4), 1-11.

Read, J. (2000). Assessing vocabulary. United Kingdom: Cambridge University Press.

Schmitt, N. (1997). Vocabulary learning strategies. In N. Schmitt \& M. McCarthy (Eds.), vocabulary: description, acquisition, and pedagogy. (pp.199-227). Cambridge: Cambridge University Press.

Schmitt, N. (2000). Vocabulary in language teaching. Cambridge: Cambridge University Press.

Tek, A. F. (2006). A survey on vocabulary learning strategies used by students at Osmangazi super high school. Unpublished MA thesis. Near East University, Nicosia, North Cyprus.

Timmers, M. \& Fischer, A. H. et al. (1998). Gender differences in motives for regulating emotions. Personality \& Social Psychology Bulletin, 24

Thornbury, S. (2005). How to teach vocabulary. Harlow: Pearson. 